\title{
Meningomyeloselli 50 yenidoğanın prospektif-gözlemsel değerlendirilmesi
}

Prospective-observational evaluation of the 50 meningomyelocele neonates

\author{
Senem Alkan Özdemir ${ }^{1} \quad$ Nail Özdemir ${ }^{2} \quad$ Esra Arun Özer ${ }^{3}$ \\ ${ }^{1}$ Dr. Behçet Uz Çocuk Hastanesi ve Cerrahisi Eğitim ve Araştırma Hastanesi, Neonatoloji Kliniği, İzmir, \\ Türkiye \\ ${ }^{2}$ Izmir Tepecik Eğitim ve Araştırma Hastanesi, Beyin ve Sinir Cerrahisi Kliniği, İzmir, Türkiye \\ ${ }^{3}$ Muğla Sıtkı Koçman Üniversitesi Tıp Fakültesi, Neonatoloji Bilim Dalı, Muğla, Türkiye
}

\section{Öz}

Amaç: Yenidoğan yoğun bakım ünitesine meningomyelosel tanısıyla yatııılan hastaların klinik sonuçları ile annenin sosyodemografik özelliklerini araştırmayı amaçladık.

Gereç ve Yöntem: Ocak 2012 - Aralık 2014 tarihleri arasında meningomyelosel nedeni ile yatan tüm yenidoğanların perinatal bilgileri, annenin sosyodemografik özellikleri, prenatal tanısı, kesenin özellikleri, operasyon zamanı, hastanede yatış süresi, eşlik eden ek anomalileri, ventriküloperitoneal şant gerekliliği, şant enfeksiyonu, taburculuk sonrası poliklinik kontrolleri ile hastaneye yatış sıklı̆ı ve yatış nedenleri prospektif-gözlemsel olarak kaydedildi. Denver Gelişimsel Tarama Testi-II ile postnatal 18. ayda psikomotor değerlendirme yapıldı ve çocuklar normal, sınırda gerilik ve ciddi gerilik şeklinde sınıflandı.

Bulgular: İki yılda yatııılan 50 hastanın ortalama doğum ağırlığı $3012 \pm 485$ (1850-4000) g, gestasyon haftası $37.9 \pm 1.4(35-42)$ hafta idi. Hiçbir anne prekonsepsiyonel dönemde folik asid kullanmamıştı. Gebelikte \%90'ında kullanım yoktu. Keselerin $25^{\prime} \mathrm{i}$ torakolomber, 24 'ü lumbosakral ve 1 'i servikotorasik yerleşimliydi. Alt ekstremite muayenesinde 27 yenidoğan paraplejik, 11 'i minimal ve 12 'si ise tam hareketliydi. Ortalama operasyon günü $4.9 \pm 3$ gündü. Hidrosefali 35, hidronefroz 33, Chiari tip 2 malformasyonu 24, pes ekinovarus 22, kifoz 16 yenidoğanda mevcuttu. Denver Gelişimsel Tarama Testi-II ile 14 bebekte normal, 31 bebekte sınırda ve 5 bebekte ise ciddi gerilik saptandı.

Sonuç: Gebelikte folik asid alınması, tüketilen gıdalardaki folik asid miktarının artııııması ve kadınların eğitimi meningomyeloselin insidansının azaltılmasında önemlidir.

Anahtar Sözcükler: Folik asit, meningomyelosel, nöral tüp defekti, yenidoğan.

\section{Abstract}

Aim: We aimed to analyze the clinical outcomes and maternal sociodemographic features of the patients followed in the neonatal intensive care unit with meningomyelocele diagnosis.

Materials and Methods: Babies with meningomyelocele followed in the unit between January 2012 and December 2014 were analyzed prospectively and observationally. Perinatal data, maternal sociodemographic features, prenatal diagnosis, features of the sac, operation time, hospitalization duration, associated abnormalities, need of ventriculoperitoneal shunt, shunt infection, controls of policlinic, rehospitalization frequency and causes for each baby were recorded. Eighteen months after birth, children were assessed by the Denver Development Screening Test-II for psychomotor delay and the children were classified as normal, borderline delay and significant delay.

Results: Fifty neonates admitted to the unit were diagnosed as meningomyelocele during the study period. Mean birth weight and gestational age were $3012 \pm 485$ (1850-4000) $g$ and $37.9 \pm 1.4$ (35-42) weeks, respectively. 90\% of the mothers had never used folic acid during pregnancy. Twenty-five of sacs were located in the lumbosacral, 24 in the thoracolumbar, and 1 in the cervicothoracic regions. Paraplegia was determined in 27 neonates. Mean operation time was within $4.9 \pm 3$ days. Among all neonates, 35 were diagnosed as hydrocephaly, 33 as hydronephrosis, 24 as Chiari type 2 malformation, 22 as pes equinovarus, and 16 as kyphosis. Denver Development Screening Test-II were normal in 14 babies whereas borderline delay in 31 and significant delay in 5.

\footnotetext{
Yazışma Adresi: Senem Alkan Özdemir

Dr.Behçet Uz Çocuk Hastanesi ve Cerrahisi Eğitim ve Araştırma Hastanesi, Neonatoloji Kliniği, İzmir, Türkiye

Makalenin Geliş Tarihi: 12.01.2017 Kabul Tarihi: 22.02.2017
} 
Conclusion: Educating women, folic acid use during pregnancy and fortification of food seem to be the important for reducing incidence of meningomyelocele.

Keywords: Folic acid, meningomyelocele, neural tube defect, neonate.

\section{Giriş}

İntrauterin yaşamda nöral tüp üçüncü haftada kapanmaya başlar. Eğer kapanma gerçekleşmezse nöral tüp defektleri (NTD) olarak adlandırılan ansefalosel, meningomiyelosel ve ayrık omurilik malformasyonu vb. şeklinde defektler ortaya çıkar (1). NTD'leri en sık görülen konjenital malformasyonlardandır. Dünyada 1000 doğumda 1-6.5 oranında görülür. NTD'lerinin etiyolojisi multifaktöryel olup hem çevresel hem de genetik pek çok faktör rol oynamaktadır. Bir ailenin bir çocuğunda NTD olması halinde bir sonraki gebelikte tekrarlama riski de \%2-3 oranında artmaktadır. Irk, coğrafi şartlar, sosyoekonomik durum, beslenme, vitamin eksiklikleri (B12 eksikliği gibi), antiepileptik ilaç (valproik asid, karbamazepin), obezite ve hipertermi literatürde tanımlanmış risk faktörleri olarak bilinmektedir. Ülkemizde sık görülen bir sorun olan maternal diabetes mellitusta (DM) NTD görülme sıklığını 3 kat arttırır (2). NTD'lerinin önemli bir kısmını oluşturan meningomyeloselden (MMC) opere edilen bebeklerin uzun dönem izlemlerinde iskelet deformiteleri, nörojenik mesane, mental gerilik ve nörolojik sorunlar olabilmektedir (3). Son çalışmalarda intrauterin dönemde onarım yapılabileceğine dair çalışmalar olsa da ülkemizdeki yaygın yaklaşım doğum sonrası MMC kesesinin onarımı ve hidrosefali eşlik etmesi halinde ventrikülo-peritoneal (VP) şant yerleştirilmesidir $(4,5)$.

$\mathrm{Bu}$ prospektif-gözlemsel araştırmamızda; 2012-2014 yılları arasında yenidoğan ünitemize yatan ve MMC nedeni ile opere edilerek izlenen bebeklerin annelerinin sosyodemografik yapılarının özellikleri, MMC kesesine eşlik eden diğer anomaliler, yenidoğanların hastanede yatış süreleri, taburculuk sonrası komplikasyonlarının belirlenmesi ve uzun dönem izlemlerinin değerlendirilmesi amaçlandı.

\section{Gereç ve Yöntem}

1 Ocak 2012 - 31 Aralık 2014 tarihleri arasında İzmir Tepecik Eğitim ve Araştırma Hastanesi Yenidoğan Yoğun Bakım Ünitesine MMC nedeni ile yatan tüm yenidoğanlar çalışmaya alındı. Hastaların verileri prospektif-gözlemsel olarak kaydedildi. Çalışmamızın etik kurul onayı, T.C Sağlık Bakanlığı Türkiye Kamu Hastaneleri Kurumu İzmir İli Kamu Hastaneleri Birliği Kuzey Sekreterliği Tepecik Eğitim ve Araştırma Hastanesi Yerel Etik Kurulundan alınmıştır. Hastaların yatışları sırasında perinatal bilgileri (cinsiyet, doğum şekli, gestasyon haftası, doğum ağırlığı), annenin sosyodemografik özellikleri (yaşı, eğitim seviyesi, folik asid kullanımı, DM varlığı, obezite ve sistemik hastalık yönünden sorgusu), prenatal tanı alıp almadığı, kesenin özellikleri (yeri, rüptüre olup olmaması), operasyon zamanı, hastanede yatış süresi, eşlik eden ek anomaliler açısından incelenmesi (kifoz, hidrosefali, renal bozukluklar, ayak deformiteleri) VP şant gerekliliği ve şant enfeksiyonu, yara yeri enfeksiyonu, taburculuk sonrası poliklinik kontrolleri (nefroloji, fizik tedavi poliklinik kontrolü), taburculuk sonrası hastaneye yatış sıklığı ve yatış nedenleri açısından kayıt edildi. Çalışmaya alınan hastaların tümü hem preoperatif hem de postoperatif dönemde izlendi. Eğer kese açık ise ampisilin ve sefotaksim tedavisi klinik protokolümüze uygun olacak şekilde başlandı ve operasyon sonrası 24 saat boyunca devam edildi. Taburculuk sonrası bilgiler için aileler telefonla arandı ve görüşmeye çağrıldı. Çağrılan tüm bebekler Denver Gelişimsel Tarama Testi (DGTT- II) ile postnatal 18. ayda psikomotor gelişimleri değerlendirildi ve normal, sınırda gerilik ve ciddi gerilik olacak şekilde 3 grupta sınıflandı.

\section{Istatistiksel yöntemler}

Hastaların klinik özellikleri demografik istatistik yöntemi ile değerlendirildi. Değerler ortalama \pm standart sapma olarak verildi. SPSS 16.0 programı kullanılarak nonparametrik veriler ki kare testi ile, risk faktörlerinin belirlenmesi ve değişkenler arasındaki ilişki ise korelasyon analizi ile değerlendirildi.

\section{Bulgular}

\section{Demografik değerlendirmeler}

İki yıllık sürede ünitemize 3090 bebek başvurmuş olup bunların 50 tanesinde MMC mevcuttu. Ortalama doğum ağırlığı $3012 \pm 485$ (1850-4000) gram olup, gestasyon haftası $37.9 \pm .4(35-42)$ hafta idi. Demografik veriler Tablo 1'de sunulmuştur.

Annelerin ortalama yaşı 30.1 \pm 5.6 (19-43) idi. Annelerin eğitim düzeyi sorgulandığında ise 27 annenin (\%54) hiç eğitim almadığı, 20 annenin (\%40) ortaöğretim mezunu olduğu ve 3 annenin (\%6) ise lise ve üzeri eğitim aldıkları görüldü. Hiçbir annenin prekonsepsiyonel dönemde folik asid kullanmadığı öğrenildi. Annelerin gebelikte folik asid kullanımı sorgulandığında ise \%90'ında kullanımın olmadığı görüldü. Ayrıca, 15 annenin gebelikte sigara içiciliğinin devam ettirdiği saptandı. Otuz bir bebeğin antenatal tanısının olduğu ve bu ailelere terminasyon önerildiği öğrenildi. Ancak ailelerin hiçbirinin kabul etmediği ve aynı zamanda 3 ailenin de daha önce NTD olan bebeklerinin bulunduğu belirlendi.

Yenidoğanların tümü ailelerinden onam alınarak opere edildi. 50 MMC'li yenidoğanın keselerinin 25 tanesi torakolomber, 24 tanesi lumbosakral ve 1 'i servikotorasik 
yerleşimliydi (Şekil-1). Ortalama operasyon günü $4.9 \pm 3$ gün olup, bebeklerin tamamına operasyon öncesi ve sonrasında antibiyoterapi verildi.

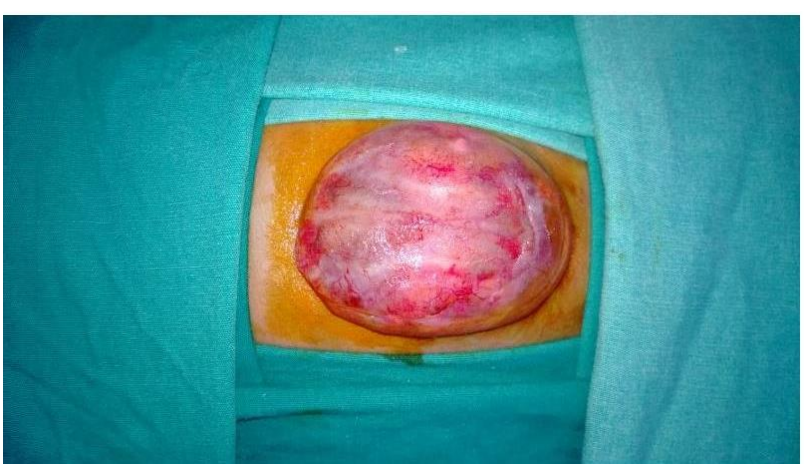

Şekil-1. Cerrahiye alınan lomber MMC'li bir yenidoğan hastamız.

Tablo-1. Çalışmaya Alınan Hastaların Demografik Verileri.

\begin{tabular}{lc}
\hline Hastalar & n: $\mathbf{5 0}$ \\
\hline Cinsiyet (E/K) & $26 / 24$ \\
\hline Doğum kilosu (g) & $3012 \pm 485$ \\
\hline Gestasyon haftası (hafta) & $37.9 \pm 1.4$ \\
\hline Doğum şekli (NSD/SCA) & $6 / 44$ \\
\hline Çoğul Gebelik & 1 \\
\hline Postnatal ayı & $10.3 \pm 4.2$ \\
\hline Anne yaşı & $30.1 \pm 5.6$ \\
\hline Operasyon günü & $4.9 \pm 3$ \\
\hline Antenatal enfeksiyon & $3(\% 6)$ \\
\hline Maternal sigara kullanımı & $15(\% 30)$ \\
\hline Maternal alkol kullanımı & 0 \\
\hline Maternal folik asid kullanımı & \\
Düzenli kullanım & 0 \\
Düzensiz kullanım & $9(\% 28)$ \\
Hiç kullanmamış & $41(\% 82)$ \\
\hline Annenin Eğitim Seviyesi & \\
Hiç eğitim almamış & $27(\% 54)$ \\
İlkokul-ortaokul mezunu & $19(\% 38)$ \\
Lise ve üzeri & $3(\% 6)$ \\
\hline Ailede MMC tanılı hasta & $3(\% 6)$ \\
\hline Antenatal tanı & $33(\% 66)$ \\
\hline${ }^{*}$ NSD: Normal spontan doğum, SCA: Sezaryen ile doğum.
\end{tabular}

\section{Anomalilerin değerlendirilmesi}

Bebeklerin anomali açısından taramaları yapıldığında hidrosefalinin en sık eşlik eden anomali olduğu izlendi ve 35 bebekte (\% 70) mevcuttu. Bu bebeklerin 30'una VP şant uygulandı ve 7 bebeğe şant enfeksiyonu (\% 23) nedeni ile şant revizyonu yapıldı. Bebeklerin alt ekstremitelerinin nörolojik muayenesinde 27 yenidoğanın paraplejik, 11'inde minimal hareket ve 12'sinde tam hareket olduğu izlendi. MMC lokalizasyonu torakolomber yerleşimli olan tüm bebeklerimiz ( 25 torakolomber MMC) ile lumbosakral yerleşimli 2 bebeğimiz paraplejik idi. Lokalizasyonu lumbosakral olan 11 MMC'li bebek ve servikotorasik yerleşimli 1 bebeğimizin alt ekstremiteleri tam hareketli iken; lumbosakral yerleşimli 11 bebeğimizin ise alt ekstremitelerinde minimal hareket izlendi. Operasyon öncesi hareketli veya minimal hareketli olan bebeklerin postoperatif dönemde hareketlerinde kötüleşme olmadığı görüldü. Yenidoğanların 24'ünde (\%48) Chiari tip 2 malformasyonu, 16'sında (\%32) kifoz, 22'sinde (\%44) pes ekinovarus deformitesi mevcuttu. Grade 1-2 hidronefroz 24 hastada (\%48), Grade 3-4 hidronefroz 9 hastada (\%18) izlendi. $\mathrm{Bu}$ bebeklerin 18 aylık izlemlerinde, 16 bebekte temiz aralıklı kateterizasyon intiyacı olduğu görüldü. Operasyon yeri yara yeri enfeksiyonu oranımız \%10'du. Takip süresince mortalitemiz yoktu (Tablo-2).

Tablo-2. Çalışmaya Alınan Olguların Eşlik eden Anomaliler Yönünden İncelenmesi.

\begin{tabular}{lcc}
\hline Hastalar & $\mathbf{n : ~} \mathbf{5 0}$ & $\%$ \\
\hline Pes ekinovarus & 22 & 44 \\
\hline Pes ekinovarus tedavisi alan & 18 & 36 \\
\hline Kas Gücü & & \\
Paraplejik & 27 & 54 \\
Minimal hareket & 11 & 22 \\
Hareketli & 12 & 24 \\
\hline Kraniyal Patolojiler & 35 & \\
Hidrosefali & 24 & 40 \\
Kifoz & 16 & 32 \\
Chiari tip 2 malformasyonu & 0 & 0 \\
\hline Kromozomal anomali & 0 & \\
\hline Major yapısal kardiak anomali & & 0 \\
\hline Renal Patolojiler & 24 & 48 \\
$\quad$ Grade 1-2 hidronefroz & 9 & 18 \\
$\quad$ Grade 3-4 hidronefroz & 3 & 6 \\
Hidronefroz+ ek patolojiler &
\end{tabular}

\section{Uzun dönem izlemlerin değerlendirilmesi}

Hastalar postnatal 18. ayda DGTT-II ile değerlendirildi. Bu test, 0-6 yaş arasındaki çocuklara uygulanmak üzere düzenlenmiştir. Çocuğun yaşına uygun becerilerini değerlendiren bu test; belirti vermemiş olan gelişimsel sorunları taramada, kuşkulu durumları nesnel bir ölçütle doğrulamada ve gelişimsel açıdan risk altındaki çocukları (örneğin perinatal sorunlar geçirmiş bebekleri) izlemede değerlidir. DGTT-II, çocuğun işlevlerdeki becerisini yaşıtları ile karşılaştırır. DGTT-II, 4 alanda değerlendirme yapmaktadır: kişisel-sosyal, ince motor, kaba motor ve dil. Skorlar bu 4 alandaki yeteneğine göre belirlenir ve benzer yaş grubundaki çocuklara göre kıyaslanır. Skorların normale yakın ve \%20 altı normal, \%20-30 arası sınırda, \%30'un üzerinde olması ise ciddi gerilik olarak tanımlanmaktadır (6). Baş çevresi, kraniyal sinir fonksiyonları, kas gücü, koordinasyon, postür ve refleksler nörolojik muayene kapsamında değerlendirildi. Motor gelişim aynı yaştaki sağlıklı çocuklarla kıyaslandı ve normal, hafif gerilik, orta gerilik ve ciddi gerilik olarak gruplandırıldı (7). Bu değerlendirmeler ışığında; 14 bebekte normal gelişim ve 31 bebekte sınırda bir gelişim saptandı. 5 bebeğin ise tüm basamaklarda geri olduğu görüldü (Tablo-3). Hastaların taburculuk sonrası tekrar hastaneye yatışı sıklıkları değerlendirildiğinde bebeklerin 
19'unun taburculuk sonrası hastaneye tekrar yatmadığı, 21 bebeğin 1-5 kez hastane yatışının olduğu ve 10 bebeğin ise beş defadan fazla yatışının yapıldığı izlendi.

Tablo-3. Olguların Denver Gelişim Testi-2 ile Değerlendirilmesi.

\begin{tabular}{lcc}
\hline & $\mathbf{n : 5 0}$ & Yüzde (\%) \\
\hline Normal Gelişim & 14 & 28 \\
İnce motor gerilik & 13 & 26 \\
Kaba gerilik & 18 & 36 \\
Tüm basamaklarda gerilik & 5 & 10 \\
\hline
\end{tabular}

\section{Tartışma}

Gelişmiş ülkelerde özellikle 1960'dan sonra folik asid desteğinin sağlanması ile NTD insidansı 1/1000'e kadar düşmüştür. Ancak gelişmekte olan ülkelerde NTD hala ciddi bir sorun olarak devam etmektedir (8,9). Prekonsepsiyonel folik asid desteğinin tam olarak etki mekanizması bilinmese de $\% 60-70$ oranında nöral tüp defektlerinde azalma sağladığı görülmüştür $(8,10)$. Yapılan gözlemsel çalışmaların sonucunda; Amerika Birleşik Devletleri Halk Sağlığı Birimi, gebeliğin ilk 3 ayında tüm gebe kadınların günlük 400 mikrogram $(\mu \mathrm{g})$ folik asit almasını önermiştir (9). Yine İngiltere Halk Sağlığı Birimi, daha önce NTD'li bebeği olan kadınlara günlük $5 \mathrm{mg}$ folik asit önerirken, diğer anne adaylarının günlük $0.8 \mathrm{mg}$ folik asit almasının yeterli olduğunu bildirmiştir (11). Bu öneriler ışığında gelişmiş birçok ülkede kadınlar hamilelikten en az 1 ay önce günlük 400 $\mu \mathrm{g}$ folik asid almaya başlarlar ve bu folik asid desteğine en az 3 ay devam ederler (9). Folik asid kullanım oranı bizim çalışmamızda \%10 bulunmuştur. Folik asitin besinlere eklenilmesi ile ABD'de \%19, Kanada'da \%46 oranında NTD oluşumda azalma sağlanmıştır (12). Bu azalma hem folik asid desteğinin sağlık politikalarına düzenli olarak eklenilmesi hem de prenatal tanı konulması yöntemlerinin geliştirilmesi ile sağlanmıştır. Ülkemizde MMC sıklığının fazla olmasından dolayı, gebelerin folik asid kullanımı açısından daha dikkatli olunması ve bu konuda gerekli hassasiyetin gösterilmesi elzemdir.

Çalışmamızda dikkat çekici sonuçlardan birisi ailelerin \%66'sının antenatal tanısının olmasına rağmen gebeliğin terminasyonunun hiçbir aile tarafından kabul edilmemesidir. Gebeliğin devam ettirilmesi geleneksel yaklaşımların tercih edildiği toplumlarda sık olarak izlenmektedir.

MMC; sadece yenidoğan yoğun bakım yatışı gerektirecek bir hastalık olmasından öte, uzun dönemde sık poliklinik izlemi ve hastaneye yatış gerektiren ve bazen de hayati tehlike yaratabilecek ciddi morbiditelere sebep olabilen bir durumdur. MMC'ye sıklıkla pek çok ek anomali eşlik eder. Nitekim hastalarımızın \%48'inde hayati komplikasyonlara yol açabilecek olan Chiari tip 2 malformasyonun eşlik ettiği görüldü. Çalışmamızda en sık eşlik eden anomali hidrosefali olarak bulunmuş ve bu hastaların \%60'ına kesenin onarılmasından sonra VP şant takılmıştır. Renal patolojilerin çalışmamızda ikinci sıklıkta eşlik eden anomali olduğu görülmüştür.

Yine çalışmamızdaki bebeklerin \%42'sinin en az 1 defa, $\% 20$ 'sinin de en az 5 defa yatış gerektiren hastalık geçirdiği saptandı. Sık ve uzun süren hastane yatışları hem aileler hem de hastaneler açısından ciddi maliyetlere yol açabilmektedir. Yatış sıklıklarının azaltılabilmesi için poliklinik takiplerinin düzenli olması önem arz eder. Ayrıca çalışmamızda \%70 oranında poliklinik kontrollerinde tutarlılık olduğu izlenmiştir. Amerika Birleşik Devletleri verileri ile kıyaslandığında düşük gibi gözükse de ülkemiz için kabul edilebilir bir oran gibi gözükmektedir.

Yapılan çalışmalarda annenin eğitim düzeyi ile $M M C$ arasında ilişki olduğu gösterilmiştir. Bu sonuçlara benzer şekilde, çalışmamızda \%54 annenin hiç eğitim almadığını, \%38'inin ise ilköğretim mezunu olduğunu saptadık. Folik asid kullanımı ile annenin eğitim düzeyi arasında ters orantı olmasından dolayı eğitim düzeyi düşük gebeler MMC açısından daha fazla risk altındadır. Yapılacak olan eğitim programları özellikle düşük sosyokültürel seviyeye sahip aileleri hedef almalı ve bu programlarda kolay anlaşılır bir üslup tercih edilmelidir.

Çalışmamızda ortalama operasyon günü $4.9 \pm 3$ gün olup, hastalarımızın büyük kısmı ilk 96 saat içinde opere edilmiştir. MMC kesesi enfeksiyon riskini azaltmak için olabildiğince erken kapatılmaya çalışılmalıdır ve ideal operasyon zamanı doğumdan sonraki ilk 48 saat olarak belirtilmektedir (13). Ancak operasyon öncesi gerekli görüntülemelerin yapılması ve teknik sorunlardan dolayı pek çok merkezde bu süre çoğunlukla uzamaktadır. Kliniğimizde ilk 48 saat içinde opere edilen olgu sayısı çok fazla olmasa da büyük kısmı ilk 96 saatte kapatılmış ve yara yeri enfeksiyonu sadece 5 vakada olmuştur. Operasyon öncesi ve sonrası kliniğimizin protokolüne uygun şekilde antibiyoterapi başlamış olmamız da enfeksiyon oranının düşük olması ile ilişkilendirilebilir. MMC'li bebeklerin ilk 6 ayda opere edilmemesi halinde ölüm oranı \%65-75 oranındadır. Opere edilmiş olgularda ilk yılda \%30-40, 3-5 yas civarı ise \% 50-60 oranında ölüm olabilmektedir $(14,15)$. Çalışmamızda hastaların iki yıllık izlemlerinde mortalite hiç yoktu. Bu durum tüm bebeklerin doğumdan hemen sonra yenidoğan yoğun bakıma alınmaları ve postoperatif dönemde yakın izlenmeleri ile ilişkilendirilebilir.

Yara yeri enfeksiyonu farklı çalışmalarda \%1 ile \%7 arasında değişiklik göstermektedir (16). Çalışmamızda yara yeri enfeksiyonu \%10'du ve bizim oranımızın literatürdeki çalışmalara kıyasla daha yüksek olmasının kese kapatılmasının biraz daha geç olmasından kaynaklanabileceği kanısındayız

DGTT-II, 0-6 yaş çocuklarının gelişimsel değerlendirilmesinde kullanılan bir tarama testidir. DGTT-II, sağlıklı görünümdeki çocuklarda olası 
gelişimsel sorunları saptamak amacı ile kullanılır. Kapsadığı kişisel-sosyal, ince motor, dil ve kaba motor alanlarda çocuğun kendi yaş grubundaki diğer çocuklarla karşılaştırılarak hangi yüzdelik diliminde olduğunu göstermesi açısından diğer birçok gelişimsel tarama testine göre daha kolay uygulanma özelliği taşımaktadır (6). Çalışmamıza alınan tüm çocuklar postnatal 18. ayda DGTT-II ile değerlendirildi ve 14 çocuk tamamen normal olarak değerlendirildi. 13 bebekte ince motor hareketlerde 18 bebekte de kaba motor hareketlerde olmak üzere 31 bebekte sınırda gerilik saptandı. 5 bebekte ise ciddi gerilik mevcuttu. Gerilik olan tüm bebeklere özel eğitim desteği verilmesi önerisiyle aileler bu programlara yönlendirildi.

\section{Sonuç}

MMC ülkemiz için çok ciddi bir sorundur. Önlenebilir bir sorun olmasına rağmen halk sağlığı hizmetleri ve toplum bilgilendirmesinde yetersizlik vardır. Kadınların eğitim düzeyinin yükseltilmesi, prekonsepsiyonel dönemde folik asid replasmanının başlatılması ve gebeliğin ilk 3 ayında devamı gibi girişimler, MMC'nin önlenmesinde en önemli köşe taşlarıdır. Tüketilen gıdalardaki folik asid miktarının arttırılması işlemi kadınların eğitim düzeyinin yükseltilmesinden daha kolay gibi gözükmektedir. Prenatal tanı oldukça önemli olmasına rağmen aileler sosyal ve dini inanışlardan dolayı gebeliğin terminasyonuna yanaşmamaktadır. MMC'li bebeklerin deneyimli merkezlerde doğması ve sonrasında da neonatolog ile beyin ve sinir cerrahisinin koopere olarak çalışıp operayonun en erken dönemde yapılmasının mortalite ve morbiditeyi azalttığı ve uzun dönem sonuçları iyileştireceği kanısındayız.

\section{Kaynaklar}

1. Nievelstein RA, Hartwiq NG, Vermeji-Keers C, Valk J. Embriyonic development of the mammalian caudal neural tube. Teratology 1993;48 (1):21-31.

2. Mitchell LE, Adzick NS, Melchionne J, Pasquvariella PS, Suttan LN, Whitehead AS. Spina bifida. Lancet 2004;364(9448):1885-95.

3. Karabaglı P, Gurcan T, Celik ZE, Karabaglı H. Myelomeningoceles and meningoceles: A clinicopathologic study of 43 cases.J Neurol Sci (Turk) 2014;31(2):335-45.

4. Oakeshott P, Hunt GM, Poultan A, Reid F. Expectation of life and unexpected death in open spina bifida: A 40-year complete, non-selective, longitudinal cohort study. Dev Med Child Neural 2010;52(8):749-53.

5. Kahn L, Mbabuike N, Valle-Giler EP, et al. Fetal surgery: The ochsner experience with in utero spina bifida repair. Ochsner $\mathrm{J}$ 2014;14(1):112-8.

6. Frankenburg WK, Doddr J, Archer P, Shapino H, Bresnick B. The Denver II: A major revision and restandardization of the Denver Development Screening Test. Pediatrics 1992;89(1):91-7.

7. Tekgul H, Gauvreau K, Soul J, et al. The current etiologic profile and neurodevelopmental outcome of seizures in term newborn infants. Pediatrics 2006;117(4):1270-80.

8. Perry VL, Albright AL, Adelson PD. Operative nuances of myelomeningocele closure. Neurosurgery 2002;51(3):719-23.

9. Food and Drug Administration. Food standarts of identity for enriched grain products to require addition of folic acid. Final Rule 21 CFR 1996;131(1):3702-37.

10. MRC Vitamin Study Research Group. Prevention of neural tube defects: Results of the medical research council vitamin study. Lancet 1991;338(8760):131-7.

11. Lloyd J. Folic acid and the prevention of neural tube defects. London: Department of Health. 1992

12. De Wals $\mathrm{P}$, Tairou $\mathrm{F}$, Van Allen Ml, et al. Reduction in neural-tube defects after folic acid fortification in Canada. N Eng J Med 2007;357(2):135-42.

13. Northrup H, Volcik KA. Spina bifida and other neural tube defects. Curr Probl Pediatr 2000;30(10):315-37.

14. Bowman RM, McLone DG, Grant JA, Tomita T, Ho JA. Spina bifida outcome: A 25 year prospective. Pediatr Neurosurg $2001 ; 34(3): 114-20$.

15. Rosano A, Botto LD, Botting B, Mastroiacozzo P. Infant mortality and congenital anomalies from 1950-1994: An international perspective. J Epidemiol Community Health 2000;54(9):660-6.

16. Pana D. Surgical complications of open spinal dysraphism. Neurosurg Clin N Am 1995;6(2):243-57. 